\title{
Tiotropio veiksmingumas apsaugant nuo LOPL paūmẻjimų
}

Jurgita Jackutè

LSMU MA Pulmonologijos ir imunologijos klinika

Reikšminiai žodžiai: lètinè obstrukcinẻ plaučių liga (LOPL), paūmèjimas, antiholinerginis vaistas, ilgai veikiantis beta 2 agonistas, tiotropis.

Santrauka. LOPL - progresuojanti liga, kuri labai pablogina pacientu gyvenimą ir yra svarbi mirties bei neigalumo priežastis pasaulyje. Naujausi Pasaulinės sveikatos organizacijos (PSO) duomenys rodo, kad šiuo metu LOPL serga daugiau nei 210 mln. pasaulio žmonių. Kliniškai liga pasireiškia kosuliu, skrepliavimu, pasunkejjusiu kvépavimu fizinio krūvio metu. Staigus simptomų pablogèjimas, t. y. ligos paūmèjimai, yra dažnas reiškinys, smarkiai sutrikdantis normalų kasdienį ligonio aktyvumą. Paūmèjimai turi įtakos gyvenimo kokybei, sergamumui ir mirties rizikos padidejjimui. Dažni paūmèjimai rodo ligos progresavimą. LOPL paūmejjimų profilaktika - vienas pagrindinių gydymo tikslų.

Lètinès obstrukcinès plaučiu ligos (LOPL) paūmèjimas - tai staiga pasunkèję LOPL simptomai (kosulys, skrepliavimas, dusulys), turintys itakos pacientu sveikatai. Pasikartojantys LOPL paūmẻjimai skatina ligos progresavimą bei gali ženkliai pabloginti su sveikata susijusią pacientu gyvenimo kokybę. Paūmèjimai susiję su kvėpavimo nepakankamumo simptomų ryškejji$\mathrm{mu}$, greitesniu plaučiu funkcijos blogejimu, o sunkiais atvejais ir su didesniu mirštamumu [1-6]. Paūmèjimai sutrikdo normalų kasdieni aktyvumą [17]. Pacientams, sergantiems vidutinio sunkumo, sunkia ir labai sunkia LOPL, ligos paūmejjimai nustatomi dažniau. LOPL progresuojant, dažnèja ir ligos paūmèjimai $[8,15,16]$. Pacientams, sveikstantiems po buvusio LOPL paūmejjimo, yra didesnè kartotinio paūmèjimo rizika: per metus apie 63 proc. pacientu pakartotinai hospitalizuojami gydyti paūmèjimo [11]. Kai LOPL paūmèjimai kartojasi, dažniau pacientą tenka gydyti ligoninèje, ilgesnè gydymo trukmè [8]. Kartotinis hospitalizavimas dèl LOPL paūmèjimų - didesnio mirštamumo rizikos veiksnys [11]. LOPL paūmejjimai atsiliepia ir ekonomiškai [18]. Ekonominè analizè rodo, kad apie 70 proc. visu LOPL gydymui skiriamų lešu sunaudojama paūmèjimams gydyti ligonineje $[9,10]$. Paūmèjimų skaičiaus sumažejimas gali sumažinti sergamumą bei mirštamumą ir sveikatos priežiūros išlaidas [11]. Paūmèjimų profilaktika - vienas pagrindinių LOPL gydymo tikslų [17].

\section{LOPL PAŪMĖJIMŲ PROFILAKTIKA TIOTROPIU}

LOPL paūmèjimu profilaktika tiotropiu vertinta (angl. The prevention of exacerbations with tiotropium POET$C O P D$ ) vieneriu metu trukmès daugiacentriu klinikiniu atsitiktinių imčiu paralelinių grupių dvigubai aklu tyrimu [7]. Jame dalyvavo 725 centrai iš 25 šalių. Ankstesni klinikiniai tyrimai parodè, kad tiotropis pagerina plaučių funkciją, su sveikata susijusią gyvenimo kokybę bei fizinio krūvio toleravimą [12, 13, 14]. Nustatyta, kad tiotropis sumažina LOPL paūmèjimų riziką (iskaitant paūmejimus, reikalingus stacionarinio gydymo) bei pailgina laikotarpi iki pirmojo paūmẻjimo [26, 30-32].

POET-LOPL tyrimo tikslas buvo palyginti dvieju ilgo veikimo bronchus plečiančių vaistų (tiotropio 18 $\mu \mathrm{g}$ inhaliuojamo vieną kartą per dieną naudojant HandiHaler ir salmeterolio $50 \mu \mathrm{g}$ inhaliuojamo du kartus per dieną naudojant dozuotą inhaliatorių) įtaką LOPL paūmèjimams. POET-LOPL tyrimas yra pirmasis ir didžiausias klinikinis tyrimas, skirtas palyginti du ilgo veikimo bronchus plečiančius vaistus, vartojamus palaikomajam LOPL gydymui.

POET-LOPL tyrime dalyvavo 7376 LOPL sergantys vyrai ir moterys. I tyrimą buvo įtraukiami pacientai, kurių amžius $\geq 40$ metú, rūkymo intensyvumas $\geq 10$ pakmečių, sergantys vidutinio sunkumo, sunkia ar labai sunkia LOPL, kuriems per praejusius metus buvo 


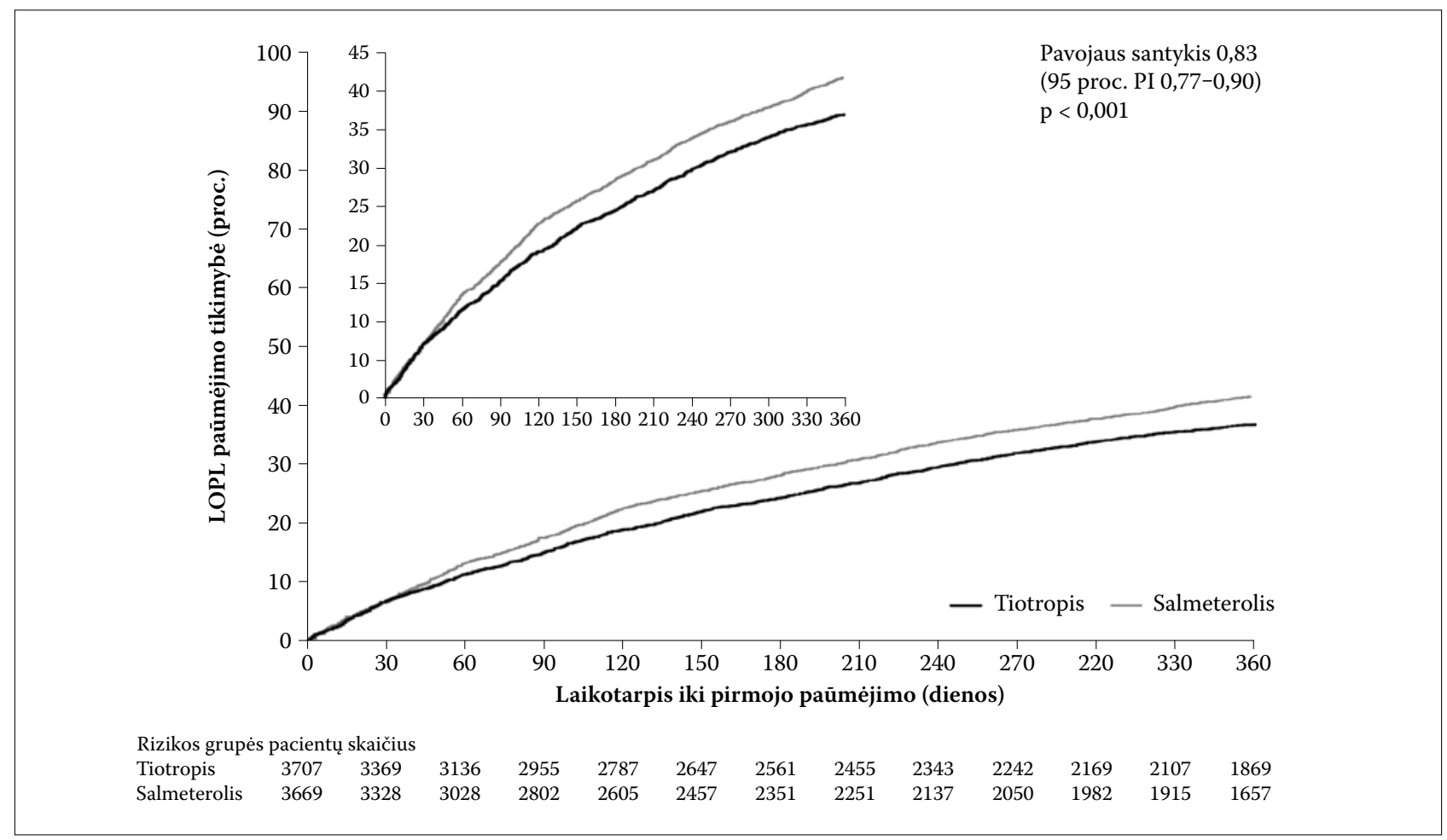

Pav. Laikotarpis iki pirmojo vidutinio sunkumo/sunkaus LOPL paūmèjimo (pirmojo vidutinio sunkumo/sunkaus LOPL paūmèjimo tikimybè)

dokumentuotas LOPL paūmëjimas, reikalingas gydymo sisteminio poveikio gliukokortikoidais ir/ar antibiotikais, ir/ar ligoninèje.

Vienas iš tyrimo tikslų buvo nustatyti laikotarpi iki pirmojo vidutinio sunkumo ar sunkaus LOPL paūméjimo. POET-LOPL tyrime paūmèjimas buvo apibrèžiamas kaip kompleksas paūmèjusių ar naujai atsiradusių simptomų (kosulio, skrepliavimo, dusulio, sunkumo krūtinèje), iš kurių bent vienas tęsiasi mažiausiai tris dienas ir turi būti gydomas vaistais (gliukokortikoidais ir/ar antibiotikais), sunkus LOPL paūmejjimas - tai paūmejjimas, kurị reikia gydyti ligoninèje. Laikotarpis iki pirmojo LOPL paūmèjimo - vienas dažniausiai naudojamų LOPL progresavimo rodiklių. Tyrime buvo vertinamas ir LOPL paūmèjimų dažnumas, sunkumas, paūmejjimams gydyti skiriami vaistai.

Pacientų pasiskirstymas pagal lytị, amžių, rūkymo intensyvumą, LOPL sunkumą, plaučių funkcijos rodiklius, papildomai vartojamus vaistus buvo panašus abiejose grupèse. Didžioji dalis ( 81 proc.) tyrimo dalyvių sirgo gretutinėmis ligomis: arterine hipertenzija (43 proc.), išemine širdies liga (10 proc.), cukriniu diabetu (7 proc.). Gretutinès ligos didina hospitalizavimo dažnumą, mirties riziką bei sveikatos priežiūros išlaidas [19, 20, 21].

Tiriamieji galejo tęsti îprastinị LOPL gydymą, išskyrus anticholinerginius vaistus ir ilgo veikimo beta 2 agonistus; salbutamolị buvo leista vartoti kaip skubiosios pagalbos vaistą. Pacientams, kurie iki ittraukimo i klinikini tyrimą buvo gydyti inhaliuojamojo gliukokortikoido ir ilgo veikimo beta 2 agonisto deriniu, tyrimo metu taikyta monoterapija inhaliuojamuoju gliukokortikoidu. Papildomai tyrimo metu daugiausia vartota vaistų obstrukcinėms kvėpavimo takų ligoms gydyti (tiotropio grupejje - 58,3 proc., salmeterolio grupeje - 58,3 proc.).

\section{KLINIKINIO TYRIMO REZULTATAI}

Tyrimo laikotarpiu diagnozuoti 4411 paūmèjimai 2691 pacientams: tiotropio grupejje - $1277(34,4$ proc.), salmeterolio - 1414 (38,5 proc.). 44 proc. paūmejjimų buvo diagnozuota vidutinio sunkumo LOPL sergantiems pacientams. POET-LOPL tyrimas rodo, kad tiotropis pailgina laikotarpi iki pirmojo LOPL paūmèjimo 42 dienomis, palyginti su salmeterolio grupe. Tiotropis 17 proc. ( $\mathrm{p}<0,001)$ sumažina bendrąją LOPL paūmejjimo riziką, palyginti su salmeteroliu (pav.). Tiotropis 14 proc. sumažino vidutinio sunkumo paūmèjimo riziką $(\mathrm{p}<0,001)$ ir 28 proc. stacionarinio gydymo reikalingo sunkaus paūmejjimo riziką ( $\mathrm{p}<0,001$ ), lyginant su salmeteroliu. LOPL paūmejjimo, kuri reikia gydyti sisteminio poveikio gliukokortikoidais, antibiotikais ar abiem vaistais, riziką tiotropis sumažino atitinkamai 23 proc., 15 proc. ir 24 proc.

Tiotropis, lyginant su salmeteroliu, gerokai pailgina laiką iki pirmojo vidutinio sunkumo ar sunkaus paūmèjimo bei sumažina metinị paūmẻjimų dažnumą pacientams, sergantiems vidutinio sunkumo, sunkia ar labai sunkia LOPL.

Dažniausi su tiriamaisiais vaistais susiję nepagei- 
daujami reiškiniai buvo kvėpavimo sistemos sutrikimai (tiotropio grupeje - 1,2 proc., salmeterolio 1,4 proc.), širdies ir kraujagysliu sistemos sutrikimai (tiotropio grupeje $-0,3$ proc., salmeterolio $-0,1$ proc.), virškinimo sistemos sutrikimai (tiotropio grupeje 0,2 proc., salmeterolio - 0,2 proc.).

7,0 proc. tiotropio grupés ir 7,9 proc. salmeterolio grupès pacientų gydymas dèl atsiradusių nepageidaujamų reiškinių buvo nutrauktas. Dažniausi nepageidaujami reiškiniai, lėmę priešlaikini gydymo nutraukimą, buvo kvėpavimo sistemos sutrikimai (tiotropio grupeje - 3,8 proc., salmeterolio - 4,6 proc.), širdies ir kraujagysliu sistemos sutrikimai (tiotropio grupeje 1,6 proc., salmeterolio - 1,3 proc.), infekcinès ligos (tiotropio grupeje - 0,9 proc., salmeterolio - 1,2 proc.). Sunkių komplikacijų kilo 545 (14,7 proc.) tiotropio grupès pacientams ir 606 (16,5 proc.) - salmeterolio, vyravo sunkus LOPL paūmejjimas. Tyrimo metu dokumentuoti 142 mirties atvejai (tiotropio grupejje 64, salmeterolio - 78). Nepageidaujamų reiškinių ir gydymo nutraukimo dẻl nepageidaujamų reiškinių dažnumas buvo panašus abiejose grupèse.

Tyrime diagnozuota 180 pneumonijos atvejų, iš kurių 158 (87,7 proc.) buvo patvirtinti radiologiškai (tiotropio grupèje - 70, salmeterolio - 88). Inhaliuojamuosius gliukokortikoidus vartojantiems pacientams pneumonija diagnozuota dažniau (89 iš 3330 pacientų, 2,7 proc.) nei tiems, kurie inhaliuojamųjų gliukokortikoidų nevartojo (59 iš 4046 pacientų, 1,5 proc.).

\section{IŠVADOS}

Tiotropis, lyginant su salmeteroliu, ženkliai pailgino laikotarpi iki pirmojo LOPL paūmèjimo ir akivaizdžiai sumažino metini paūmèjimų skaičiuc pacientams, sergantiems LOPL (nuo vidutinio sunkumo iki labai sunkios). Tiotropio nauda patvirtinta visu pogrupių pacientams. Sunkių nepageidaujamų reiškinių, lèmusių gydymo nutraukimą, bei mirties atvejų skaičius buvo panašus abiejose gydymo grupèse.

\section{PREVENTION OF EXACERBATIONS WITH TIOTROPIUM}

\section{JURGITA JACKUTE் \\ DEPARTMENT OF PULMONOLOGY AND IMMUNOLOGY LITHUANIAN UNIVERSITY OF HEALTH SCIENCE}

Keywords: chronic obstructive pulmonary disease, exacerbation, anticholinergic, long - acting beta (2) - agonist, tiotropium.

Summary. COPD is a progressive disease that restricts patients lives over time and is a major cause of death and disability throughout the world. The latest World Health Organization (WHO) figures estimate that 210 million people are currently living with COPD. Symptoms include cough, sputum production, and breathlessness (dyspnoea) on exertion. Acute worsening of these symptoms (i.e. exacerbations) often occur and can restrict a patient's ability to perform normal daily activities. Exacerbations have an impact on patients quality of life, morbidity and increase the risk of death. Frequent exacerbations indicate a progression of the disease. Prevention of exacerbations of COPD is one of the most important management goals.

\section{LITERATŪRA}

1. Seemungal TAR, Donaldson GC, Paul EA, Bestall JC, Jeffries DJ, Wedzicha JA. Effect of exacerbation on quality of life in patients with chronic obstructive pulmonary disease. Am J Respir Crit Care Med 1998;157(5):14181422.

2. Connors AF, Jr., Dawson NV, Thomas C, Harrell FE, Jr., Desbiens N, Fulkerson WJ, Kussin P, Bellamy P, Goldman L, Knaus WA. Outcomes following acute exacerbation of severe chronic obstructive lung disease. The SUPPORT investigators (Study to Understand Prognoses and Preferences for Outcomes and Risks of Treatments). Am J Respir Crit Care Med 1996:154(4):959-967.

3. Miravitlles M, Ferrer M, Pont A, Zalacain R, Alvarez-Sala JL, Masa F, Verea H, Murio C, Ros F, Vidal R. Effect of exacerbations on quality of life in patients with chronic obstructive pulmonary disease: a 2 year follow up study. Tho$\operatorname{rax}$ 2004:59(5):387-395.

4. Soler-Cataluña JJ, Martínez-García MÁ, Román Sánchez P, Salcedo E, Navarro $M$, Ochando R. Severe acute exacerbations and mortality in patients with chronic obstructive pulmonary disease. Thorax 2005;60(11):925-931.

5. Stevenson NJ, Walker PP, Costello RW, Calverley PM. Lung mechanics and dyspnea during exacerbations of chronic obstructive pulmonary disease. Am J Respir Crit Care Med 2005;172(12):1510-1516.

6. Fabbri LM, Luppi F, Beghe B, Rabe KF. Update in chronic obstructive pulmonary disease 2005. Am J Respir Crit Care Med 2006;173(10):1056-1065.

7. Beeh KM, Hederer B, Glaab T, Muller A, Rutten-van Moelken M, Kesten S, Vogelmeier C. Study design considerations in a large COPD trial comparing effects of tiotropium with salmeterol on exacerbations. Int J Chron Obstruct Pulmon Dis 2009;4:119-125.

8. Donaldson GC, Seemungal TAR, Bhowmik A, Wedzicha JA. Relationship between exacerbation frequency and lung function decline in chronic obstructive pulmonary disease. Thorax 2002;57(10):847-852.

9. Hilleman DE, Dewan N, Malesker M, Friedman M. Pharmacoeconomic evaluation of COPD. Chest 2000;118(5):1278-1285.

10. Strassels SA, Smith DH, Sullivan SD, Mahajan PS. The costs of treating COPD in the United States. Chest 2001;119(2):344-352.

11. Perera WR, Hurst JR, Wilkinson TM, Sapsford RJ, Mullerova H, Donaldson GC, Wedzicha JA. Inflammatory changes, recovery and recurrence at COPD exacerbation. Eur Respir J 2007;29(3):527-534.
12. Tashkin DP, Celli B, Senn S, Burkhart D, Kesten S, Menjoge S, Decramer M. A 4-year trial of tiotropium in chronic obstructive pulmonary disease. $\mathrm{N}$ Engl J Med 2008;359(15):1543-1554.

13. Tashkin DP, Cooper CB. The role of long-acting bronchodilators in the management of stable COPD. Chest 2004;125(1):249-259.

14. Brusasco V, Hodder R, Miravitlles M, Korducki L, Towse L, Kesten S. Health outcomes following treatment for six months with once daily tiotropium compared with twice daily salmeterol in patients with COPD. Thorax 2003;58(5):399-404.

15. Paggiaro PL, Dahle R, Bakran I, Frith L, Hollingworth K, Efthimiou J, Group obotICS. Multicentre randomised placebo-controlled trial of inhaled fluticasone propionate in patients with chronic obstructive pulmonary disease. Lancet 1998:351:773-780.

16. Gompertz S, Bayley DL, Hill SL, Stockley RA. Relationship between airway inflammation and the frequency of exacerbations in patients with smoking related COPD. Thorax 2001;56:36-41.

17. Miravitlles M, Anzueto A, Legnani D, Forstmeier L, Fargel M. Patient's perception of exacerbations of COPD--the PERCEIVE study. Respir Med 2007;101(3):453-460.

18. Wouters EF. Economic analysis of the Confronting COPD survey: an overview of results. Respir Med 2003;97(Suppl C):S3-14.

19. Agusti A, Soriano JB. COPD as a systemic disease. COPD 2008;5(2):133-138.

20. Barnes PJ, Celli BR. Systemic manifestations and comorbidities of COPD. Eur Respir J 2009:33(5):1165-1185.

21. Decramer M, Rennard S, Troosters T, Mapel DW, Giardino N, Mannino D, Wouters E, Sethi S, Cooper CB. COPD as a lung disease with systemic consequences--clinical impact, mechanisms, and potential for early intervention. COPD 2008;5:235-256.

22. Halpin D, Menjoge S, Viel K. Patient-level pooled analysis of the effect of tiotropium on COPD exacerbations and related hospitalisations. Prim Care Respir J 2009;18(2):106-113.

23. Niewoehner DE, Rice K, Cote C, Paulson D, Cooper JA, Jr., Korducki L, Cassino C, Kesten S. Prevention of exacerbations of chronic obstructive pulmonary disease with tiotropium, a once-daily inhaled anticholinergic bronchodilator: a randomized trial. Ann Intern Med 2005;143(5):317-326. 